\title{
El estudio de las urbanizaciones cerradas. Una propuesta metodológica aplicada al municipio Yerba Buena (aglomerado Gran San Miguel de Tucumán, noroeste argentino)*
}

\author{
Matilde Malizia**
}

Este artículo tiene por objetivo presentar una estrategia metodológica para el estudio de las urbanizaciones cerradas que se centre en la mirada de los actores sociales involucrados, teniendo en cuenta las representaciones sociales y las percepciones que sustentan. Dicha estrategia se enmarca en una investigación cualitativa que permite reconstruir teóricamente un objeto en permanente dinamismo y obtener una comprensión holística de las situaciones sociales; propone para su desarrollo la utilización de un enfoque etnográfico, en tanto la etnografía es una modalidad de investigación que favorece la comprensión de los procesos sociales.

Palabras clave: estrategia metodológica, actores intervinientes, investigación cualitativa, enfoque etnográfico, urbanizaciones cerradas.

Fecha de recepción: 27 de agosto de 2013.

Fecha de aceptación: 16 de junio de 2014.

The Study of Gated Communities. A Methodological Proposal Applied to the Yerba Buena Municipality (Gran San Miguel de Tucuman Agglomerate in the Northwest of Argentina)

This article seeks to present a methodological approach to the study of gated communities in order to focus on the perspective of the actors involved, taking into account the social representations and perceptions those supports. This strategy is part of a qualitative research project that enables one to theoretically reconstruct an object in constant dynamism and obtain a holistic understanding of social situations. To this end, it proposes using an ethnographic approach, since ethnography is a form of research that promotes the understanding of social processes.

* Este artículo forma parte de la tesis doctoral de la autora "Countries y barrios privados en el Gran San Miguel de Tucumán. Efectos y contrastes sociales”, dirigida por los doctores Alfredo Bolsi y Pablo Paolasso y defendida en diciembre de 2011. El trabajo de campo fue realizado durante los años 2007 y 2008, sin embargo la base de datos ha sido actualizada hasta el presente.

** Instituto Superior de Estudios Sociales (ISES), Conicet-UNT. Dirección postal: San Lorenzo 429, San Miguel de Tucumán, CP 4000, Argentina. Correo electrónico: $<$ matumalizia@yahoo.com.ar>. 
Key words: methodological strategy, actors involved, qualitative research, ethnographic approach, gated communities.

\section{Introducción: el proceso de investigación}

Hay entre los investigadores una confluencia epistemológica y temática al analizar, desde diversos campos de la ciencia, el surgimiento, el desarrollo y la expansión de las urbanizaciones cerradas en las metrópolis latinoamericanas. Estos análisis se asientan, en general, sobre tres ejes de explicación interrelacionados: el miedo, el consumo y la simulación. Postulan además la multiplicación de estos emprendimientos cerrados como una alternativa residencial en el mundo contemporáneo que reconfigura progresivamente la estructura de la ciudad. ${ }^{1}$

El miedo (ante la inseguridad que existe en la ciudad) y el consumo (promovido por las campañas de marketing de estos emprendimientos), se convierten en los elementos centrales utilizados por los promotores inmobiliarios ${ }^{2}$ para encomiar la privatización del espacio ${ }^{3}$ y el aislamiento urbano, y ofrecer las urbanizaciones cerradas (Rodríguez Chumillas, 2005). Combinan el miedo y el consumo (entendidos como dos procesos que se retroalimentan en forma permanente) con el contexto sociohistórico local y con el nivel socioeconómico de los compradores, su composición familiar, sus aspiraciones y sus percepciones en torno a la ciudad (López Levi y Rodríguez Chumillas, 2004). Simulan un microcosmos fortificado donde se exacerba el valor de la seguridad, la exclusividad, el confort y la armonía con la naturaleza, ${ }^{4}$ enfatizando ciertos valores propios del consumo, como un hogar tranquilo para vivir, rodeado de espacios verdes y lejos de los ruidos y la contaminación que caracteriza a las ciudades. ${ }^{5}$

1 Véase Cabrales Barajas, 2002; Janoschka, 2002; Méndez, 2002; Davis, 2003; Low, 2003; Hidalgo, 2004; Caldeira, 2007, entre otros.

2 Para los efectos de este artículo el término "promotor inmobiliario" incluye a los especuladores de la tierra, las agencias inmobiliarias y las empresas constructoras y comercializadoras.

${ }^{3}$ La construcción de urbanizaciones cerradas pone en evidencia ambigüedades que desdibujan lo que se considera público y lo privado al redefinir las estructuras urbanas tradicionales. Así, la privatización del desarrollo urbano se realiza en detrimento del espacio público (García Canclini, 1996; Mertins, 2003/2004).

${ }^{4}$ Lacarrieu (2002) sostiene que el recurso de la naturaleza se transformó en el articulador esencial entre diferentes elementos para dar sentido a las urbanizaciones cerradas.

${ }^{5}$ La vivienda comienza a ser entendida como un bien de consumo que ha dejado 
Rodríguez Chumillas (2005: 130) llama a la combinación de estos tres ejes "cultura del miedo" y entiende que la misma genera gradualmente consumidores que acuden al mercado inmobiliario en busca de espacios donde sentirse protegidos. Sin embargo, las urbanizaciones cerradas más que proteger de la inseguridad de la ciudad abierta ocultan a sus residentes de la mirada del otro, ${ }^{6}$ otro que se construye sobre la base de la diferencia, la diversidad o la desigualdad, pero que en definitiva se trata de un otro lejano e incierto, de un otro que estando próximo es desconocido (Boivin, Rosato y Aribas, 1999).

Teniendo en cuenta dichos ejes de análisis, este artículo tiene por objetivo presentar una estrategia metodológica para el estudio de las urbanizaciones cerradas centrada en la mirada de los actores sociales involucrados; entendiendo que el miedo, el consumo y la simulación influyen de manera decisoria en las representaciones sociales y en las percepciones que éstos sustentan ante el surgimiento, desarrollo y expansión de esta nueva lógica de ocupación del espacio urbano. Dicha estrategia metodológica se enmarca en una investigación cualitativa, la cual permite reconstruir teóricamente un objeto en permanente dinamismo y obtener una comprensión holística de las situaciones sociales (Yuni y Urbano, 2003) y propone para su desarrollo la utilización de un enfoque etnográfico, en tanto la etnografía es una modalidad de investigación que contribuye a lograr la comprensión de los procesos sociales (Hammersley y Atkinson, 1994). ${ }^{7}$

Como punto de partida es preciso tener en cuenta que las urbanizaciones cerradas suelen entenderse como parte integrante de fenómenos urbanos más amplios. Fueron concebidas como respuesta a las

atrás su carácter de necesidad básica y que en la actualidad se ha convertido en una mercancía que sigue las mismas reglas del mercado que otros objetos más superfluos (Lipovetsky, 2002).

${ }^{6}$ Siguiendo a Arizaga y Murgida (2005) la ciudad abierta se caracteriza por su condición de lugar en donde se producen intercambios con múltiples otros.

${ }^{7} \mathrm{El}$ enfoque etnográfico propuesto se basa en postulados afines a la hermenéutica de las ciencias sociales (Ricoeur, 1988; Giddens, 1989; Gadamer, 1993). Apunta a reconstruir la lógica implícita en la acción social de los sujetos, es decir, la perspectiva del actor o el "punto de vista del nativo" según el modelo canónico (Berreman, 1962; Goetz y LeCompte, 1988; Geertz, 1988 y 1989). De acuerdo con Geertz (1988) el etnógrafo se enfrenta con estructuras conceptuales complejas, a veces superpuestas o entrelazadas entre sí y al mismo tiempo no explícitas, frente a las cuales debe ingeniarse de alguna manera para captarlas primero y explicarlas después. La realidad no aparece simplemente ante el investigador, sino que éste debe tratar de develarla y producir interpretaciones de lo que vio y escuchó. Se trata de comprender los fenómenos sociales desde la propia perspectiva de los sujetos, reconociendo el lugar desde el cual los actores clasifican el comportamiento y le atribuyen sentido. 
demandas que caracterizan a un determinado grupo de la sociedad y que se relacionan, principalmente, con la necesidad de habitar lugares seguros y en contacto con la naturaleza. No obstante, en la actualidad también responden a otro tipo de demandas, entre las que se encuentran las pretensiones de exclusividad y homogeneidad social del grupo de pertenencia (Vidal Koppmann, 2007; Thuiller, 2005; Cabrales Barajas, 2004; Roitman, 2004; Borsdorf e Hidalgo, 2004; Janoschka y Glasze, 2003; Borsdorf, 2003; Janoschka, 2002; Svampa, 2001 y 2004; Carballo, 2002; Lacarrieu y Thuillier, 2001; Tella, 2000).

De este modo, la estrategia metodológica propuesta se centra en interpretar la realidad a partir del diálogo crítico y permanente entre el modelo teórico sustentado y el mundo empírico estudiado. Esta relación permanente, entonces, le permitirá al investigador captar "las pistas" que el campo presenta y atender a las categorías sociales -prácticas y discursos- (Rockwell, 1987) que sustentan los actores sociales acerca de la realidad en que se encuentran. El empleo de un enfoque etnográfico tiene como propósito estudiar a las personas insertas en un contexto determinado, sin descartar la influencia de su historia de vida y atendiendo a la comprensión de los fenómenos sociales desde la propia perspectiva de los sujetos, ${ }^{8}$ teniendo en cuenta la situación en la que se encuentran, los significados que le atribuyen a sus acciones y cómo interpretan las relaciones que se establecen dentro de su mundo social particular. ${ }^{9}$ En tal sentido los sujetos recurren a categorías de significación compartidas; las prácticas y representaciones sociales que sustentan son heterogéneas y en ellas se pueden detectar, como expresa Achilli (2005), experiencias sociales del pasado, intentos de transformarlas, y construcciones de sentidos en relación con lo vivido y con aquello que supone el porvenir. Esto implica reconocer que las prácticas y las representaciones sociales son el resultado de una actividad continua en la que los individuos

${ }^{8}$ El fenómeno de las urbanizaciones cerradas ha sido ampliamente estudiado desde una perspectiva teórica en la cual se analizan estos emprendimientos como parte de procesos metropolitanos más amplios que provocan diversas transformaciones urbanas (Thuillier, 2005; Janoschka, 2005; Janoschka y Glasze, 2003).

${ }^{9}$ La comprensión de los procesos sociales combina los horizontes interpretativos del investigador con los fenómenos que trata de conocer. Según Gadamer (1993) todo comprender es interpretar y, a su vez, la interpretación se desarrolla por medio del lenguaje. Von Wright (1971) complementa esta idea cuando dice que el científico social debe comprender el significado de los datos que registra si quiere tratarlos como hechos sociales, teniendo en cuenta que dicha comprensión se alcanza por medio de la interpretación. 
ponen en juego destrezas, procedimientos y reglas (Batallán, 2007). Por lo tanto el análisis etnográfico "no responde a un procedimiento técnico idéntico para todo el estudio; el método (camino) del análisis debe marcarse en cada caso, según las características particulares del objeto de estudio" (Rockwell, 1987: 14).

El enfoque etnográfico propuesto se vale principalmente de la metodología y las técnicas cualitativas de la investigación social. En el transcurso de la investigación se llevaron a cabo, principalmente, observación con participación (Guber, 2001 y 2009), entrevistas abiertas en profundidad (Goetz y LeCompte, 1988; Taylor y Bodgan, 1990; Souza Minayo, 2004), entrevistas cortas o conversaciones informales (Taylor y Bodgan, 1990), análisis de documentos bibliográficos, oficiales y periodísticos (Yuni y Urbano, 2003) y se elaboró un catálogo fotográfico (Sontag, 2007). ${ }^{10}$ Su aplicación implicó la entrada al campo, lo que conlleva, siguiendo a Berreman (1962), diversos procesos de negociación. Para Rabey y Kalinsky (1991) la llegada del investigador al campo supone el establecimiento de un "contrato cognoscitivo" con los sujetos locales. El investigador no es neutral, requiere de una gran sensibilidad y receptividad, y debe saber que las personas con quienes desarrolla el trabajo de campo son también constructoras de conocimiento. Como expresa Cardoso de Oliveira (2004), el investigador mira, escucha y escribe. Geertz (1989: 11 y 139) explicita este proceso al decir que mirar y escuchar representan el "estar allí", en el campo, mientras que la tarea de escribir representa el "estar aquí", refiriéndose al trabajo que posteriormente el investigador efectúa en su gabinete en la academia.

\section{"Estar alli", en el campo}

\section{La unidad de estudio: el municipio Yerba Buena}

El campo como unidad de estudio (Guber, 2009) se encuentra conformado por el municipio Yerba Buena, localizado al oeste del aglo-

10 Se realizaron un total de 92 entrevistas con una duración promedio de dos horas cada una, y la selección de las personas que participaron se definió en función de su disponibilidad y accesibilidad. Para resguardar la identidad de los interlocutores se mencionan por sus iniciales, y cuando no se han identificado se registran como s/n. En cambio los nombres de las urbanizaciones cerradas y los de las agencias inmobiliarias se mantuvieron en su forma original. 
merado Gran San Miguel de Tucumán ${ }^{11}$ (noroeste argentino). Este municipio, con una superficie estimada de $38 \mathrm{~km}^{2}$, ocupa el $22.15 \%$ del total de la superficie del aglomerado y concentra la mayor cantidad de urbanizaciones cerradas de éste, ${ }^{12}$ lo cual se debe principalmente a que en el imaginario social se le considera como uno de los lugares privilegiados para vivir en tanto se ubica en el piedemonte de la Serranía de San Javier. Se trata de un área con paisajes atractivos vinculados con el entorno montañoso, espejos de agua y abundante vegetación. ${ }^{13}$

La llegada de las urbanizaciones cerradas a la región ocurrió después de su incorporación a la trama urbana del Área Metropolitana de Buenos Aires. ${ }^{14}$ Su difusión implicó la importación de nuevas formas de habitar la ciudad y de nuevos valores y estilos de vida que se relacionan con la producción de estos espacios urbanos. En el transcurso de la década de los noventa estas urbanizaciones comenzaron a multiplicarse bajo una fase de flexibilización económica y liberalización de los mercados que rompió claramente con las tradicionales pautas de estructuración urbana y favoreció las oportunidades de edificación y difusión de tales complejos. No obstante, su desarrollo exponencial apenas se produjo a partir del año $2000 .^{15}$

En el municipio Yerba Buena se identificaron 49 urbanizaciones cerradas que se clasifican en tres tipos: barrios privados, countries y

11 Este aglomerado es considerado en la jerarquía urbana nacional como una ciudad intermedia en tanto conecta, transfiere y difunde el desarrollo de su área de influencia y actúa como centro de enlace entre territorios rurales y urbanos y otros centros más o menos alejados. Dada su población estimada de 832000 habitantes (Encuesta Permanente de Hogares, segundo trimestre de 2013) es la ciudad intermedia más importante del NOA, destacándose como capital regional.

12 Se estima que aproximadamente el $95 \%$ de las urbanizaciones cerradas construidas hasta el año 2007 se localizan en el municipio Yerba Buena (Malizia, 2011).

13 De acuerdo con el Índice de Calidad Ambiental desarrollado por Velázquez y Celemin (2013), Yerba Buena se posiciona como uno de los lugares de Argentina con mejor calidad ambiental. Dicho índice surge de la combinación ponderada de los recursos recreativos de base natural (RRBN, 30\%), los recursos recreativos socialmente construidos (RRSC, 30\%) y los problemas ambientales (PA, 40\%).

14 Mientras que en Tucumán la primera urbanización cerrada -Yerba Buena Golf Country Club- se creó en el año 1978, en Buenos Aires el primer country-Tortugas Country Club- se fundó en 1930.

15 En el Área Metropolitana de Buenos Aires el crecimiento de las UC se detuvo temporalmente durante los meses que siguieron a la crisis social, política y económica que se desató en el país en diciembre de 2001. Ésta se manifestó en la paralización de las obras, la caída de las ventas inmobiliarias y el aumento del precio del suelo. En la actualidad los operadores inmobiliarios afirman que el costo de la tierra o la vivienda ha superado los valores anteriores a la crisis (Vidal Koppman, 2006). 
condominios $^{16}$ (mapa 1). La mayoría de estos emprendimientos se incorporaron a una trama urbana en vías de consolidación; se asentaron sobre todo en espacios que anteriormente se utilizaban como áreas de cultivo (principalmente plantaciones de caña de azúcar y de limoneros) y en lotes desocupados. Estos espacios se localizaban tanto en la periferia como en las proximidades de las áreas centrales del municipio (aunque siempre fuera del casco urbano tradicional), motivo que propició su rápida integración al tejido urbano (fotos 1 y 2). Ocupan una superficie estimada de 727.25 ha, se asientan sobre el $19 \%$ del total de la superficie del municipio Yerba Buena (3 800 ha) ${ }^{17}$ y su densidad poblacional es de $750.53 \mathrm{hab} . / \mathrm{km}^{2}$, mientras que la densidad aproximada del municipio es de $2255 \mathrm{hab} . / \mathrm{km}^{2}$.

La rápida expansión de las urbanizaciones cerradas en el aglomerado Gran San Miguel de Tucumán se fundamenta principalmente en criterios económicos y políticos que se encuentran avalados por las prácticamente nulas normas vigentes que regulen el desarrollo de este tipo de emprendimientos residenciales. Esta situación pone de manifiesto las lagunas existentes entre la planificación urbana y la efectiva expansión de la ciudad.

\section{La unidad de análisis: los de adentro y los de afuera}

La unidad de análisis (Guber, 2009) está conformada por los actores sociales involucrados en el fenómeno de las urbanizaciones cerradas y por las interacciones y representaciones (diversas y heterogéneas) que los mismos sostienen. El reconocimiento de sus acciones e inter-

${ }^{16}$ El barrio privado es la oferta más difundida entre las urbanizaciones cerradas y por lo general no dispone de equipamiento deportivo y recreativo para uso común. El country, en cambio, exalta la valoración de la vida al aire libre y la práctica de deportes; para ello cuenta con instalaciones deportivas y sociales de uso comunitario como canchas de fútbol, paddle y tenis, campos de golf, pileta de natación y sede social, entre otros elementos destinados al uso comunitario y familiar. Los condominios son conjuntos de residencias construidas de acuerdo con un prototipo de vivienda determinado en forma de tiras o bloques ubicados hacia uno de los costados de la calle central y única de la urbanización. No disponen de equipamiento deportivo y recreativo para uso comunitario (Malizia, 2011).

17 En la actualidad está apareciendo un nuevo tipo de emprendimiento privado: la ciudad-pueblo, que se localiza en las afueras del aglomerado en forma de islas que están desconectadas prácticamente de la mancha urbana. Dadas sus características procuran reproducir, aunque en menor escala, los megaemprendimientos construidos en las grandes metrópolis latinoamericanas, como Nordelta en Buenos Aires o Alphaville en San Pablo. 


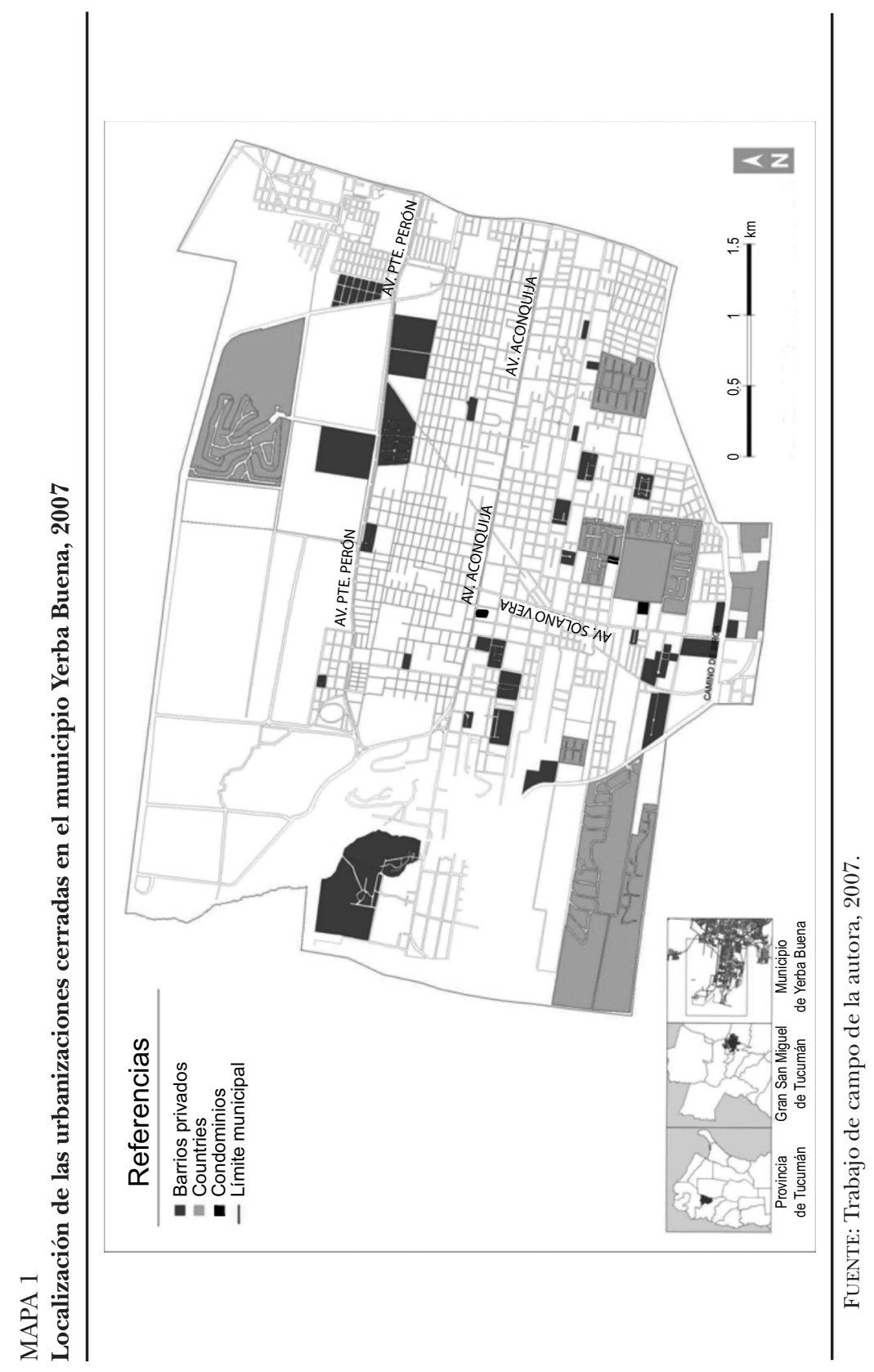


Malizia, EL ESTUDIO DE LAS URBANIZACIONES CERRADAS

FOTOGRAFÍA 1

Expansión de urbanizaciones cerradas en el municipio Yerba Buena, 2009

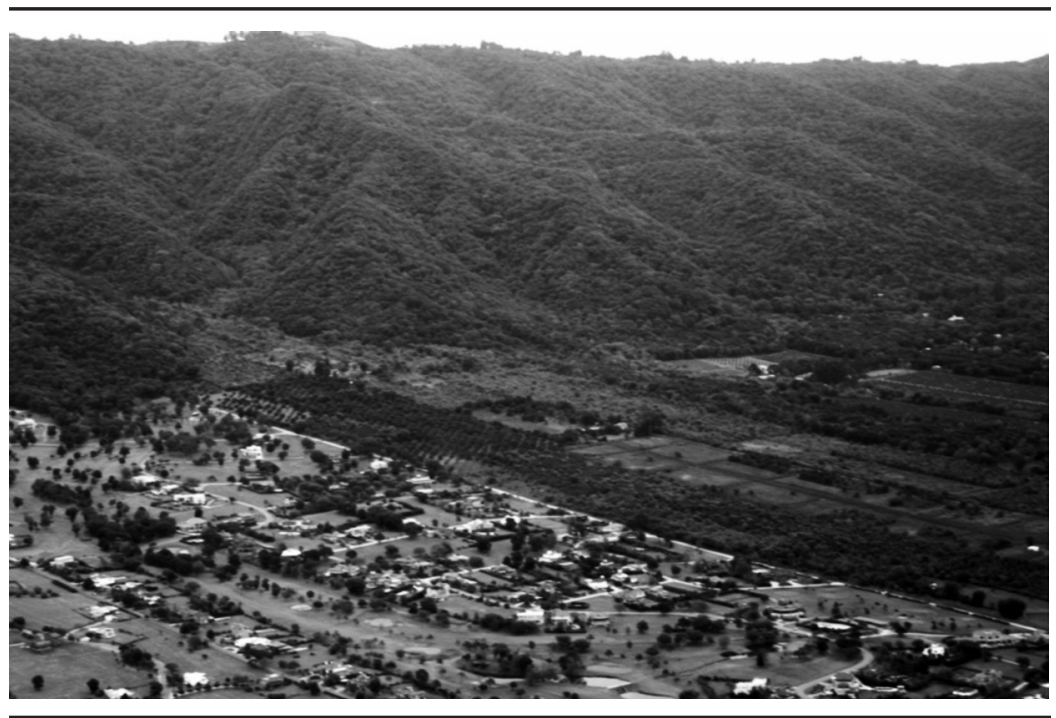

FUENTE: Catálogo de fotos de Yerba Buena organizado por la autora.

FOTOGRAFÍA 2

Expansión de urbanizaciones cerradas en el municipio Yerba Buena, 2009

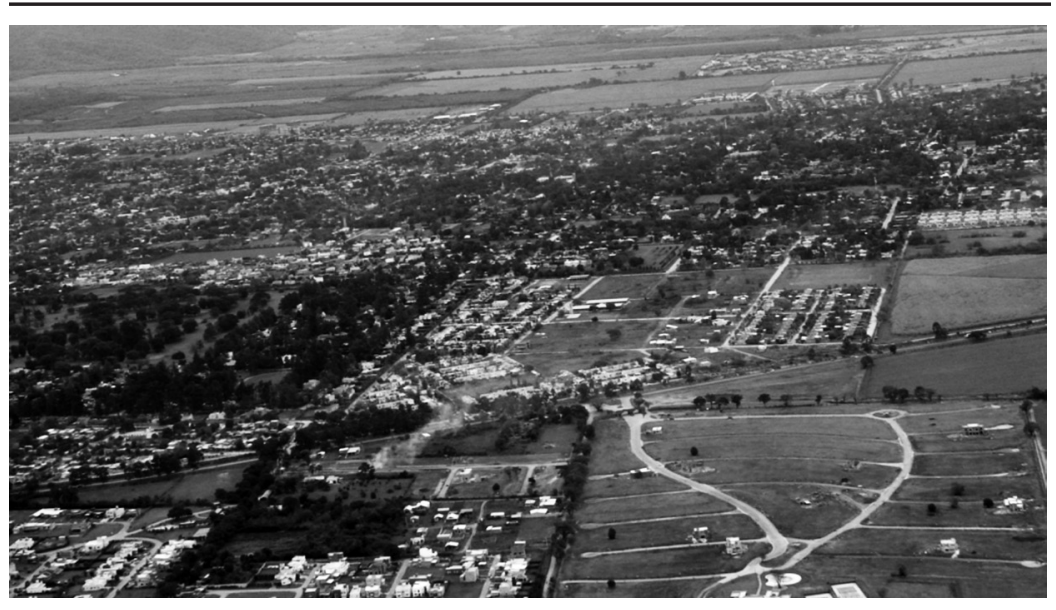

FUENTE: Catálogo de fotos de Yerba Buena organizado por la autora. 
pretaciones permitirá incorporar nuevos puntos de análisis y de comprensión de los hechos sociales. ${ }^{18}$ Se entiende que las fronteras espaciales instauradas por estos emprendimientos se transformaron en fronteras simbólicas y sociales que implican una profunda ruptura entre el adentro y el afuera de estos emprendimientos, acentuando los contrastes sociales ya existentes. "Adentro" representa la ausencia de problemas, un ámbito armónico en el cual las regulaciones son claras y los códigos de comportamiento previsibles, un espacio en donde los individuos se sienten "como en su casa". Por el contrario, "afuera" refleja un espacio en donde suceden cosas que no se pueden anticipar o comprender, donde prevalece la incertidumbre, un espacio al que las personas de adentro concurren rara vez (Svampa, 2004). Bauman (2008) explica la dicotomía del adentro y el afuera de la siguiente manera:

las vallas [los cercos] tienen dos lados [...] dividen un espacio uniforme en un "afuera" y un "adentro", pero lo que es "adentro" para los que están de un lado de la valla es "afuera" para los que están del otro lado. Los residentes de los condominios [urbanizaciones cerradas] usan la valla para estar "fuera" de la desagradable, inquietante, vagamente amenazante y dura vida de la ciudad, y "dentro" del oasis de calma y seguridad. Pero, al mismo tiempo y con el mismo gesto, impiden el acceso a los demás, dejándolos fuera de los lugares decentes y seguros [2008: 142-143].

Ahora bien, a partir de esta concepción de adentro y afuera se organiza a la unidad de análisis en dos grupos poblacionales, los de adentro y los de afuera. ${ }^{19}$ Esta clasificación, lejos de considerar a estos grupos homogéneos, tiene por objetivo diferenciar, desde un punto de vista analítico, a los residentes de los no residentes de las urbanizaciones cerradas, en tanto sus miradas y percepciones tenderán a ser diferentes según la posición que ocupan en la estructura social, la manera en que se perciben a sí mismos y al entorno en que se encuentran y cómo éste influye sobre su comportamiento y su toma de deci-

${ }_{18} \mathrm{Si}$ bien el investigador recurre inicialmente a su propio marco de referencia para interpretar la realidad, luego va modificándolo gradualmente en busca de un marco que dé cuenta de la lógica de los actores. De lo contrario se estaría imponiendo un marco de referencia ajeno a ese grupo social y violentando aquello que se estudia $(\mathrm{Gu}-$ ber, 2009).

19 En general los estudios específicos sobre las urbanizaciones cerradas contemplan sólo la participación de sus residentes. Al respecto pueden consultarse Janoschka, 2002; Svampa, 2004; Rojas, 2007; Del Cueto, 2007; Girola, 2008, entre otros. 
siones (Bourdieu, 1996). Quienes participan en cada uno de estos grupos comparten características comunes, como normas, valores, fines y posición en la estructura social, que los definen y diferencian del resto de la sociedad; sin embargo pertenecer a un mismo grupo no implica compartir las mismas condiciones sociales y económicas.

De este modo el primer grupo, los de adentro, está integrado por los residentes de las urbanizaciones cerradas (UC). En cambio el grupo los de afuera está formado por subgrupos cuyos integrantes tienen, entre otras cosas, prioridades, intereses y valores muy diversos. Son vecinos próximos a las UC, personas que trabajan en las mismas, representantes del ámbito público y privado y proveedores de bienes y servicios que se han instalado en zonas colindantes con estos emprendimientos. ${ }^{20}$ Así es que los vínculos que se entablan entre los de adentro y los de afuera de estas urbanizaciones se plantean no sólo desde la identificación más o menos mimética con el otro, sino también desde el reconocimiento de la distancia. Las percepciones que se elaboran acerca del otro se convierten en una mirada hacia arriba o hacia abajo, una mirada desde una supuesta posición social más que desde una situación real.

A continuación se caracteriza brevemente a ambos grupos poblacionales, con sus respectivos subgrupos, teniendo en cuenta, como ya se dijo, que su distinción y agrupamiento responden estrictamente a fines analíticos.

\section{Los de adentro}

Desde el punto de vista etario los grupos familiares que residen en estas urbanizaciones están compuestos en su gran mayoría por parejas jóvenes (de entre 30 y 40 años de edad aproximadamente) cuyos hijos no superan los 10 años de edad; son pocos los chicos adolescentes. En

20 Para Curtit (2003) la dinámica adentro-afuera se combina en la periferia urbana conformando espacios y grupos claramente diferenciados. En los extremos más contrastantes de esa diferencia se ubican los grupos de mayor y menor poder adquisitivo. Los primeros encuentran adentro de las UC la pertenencia a un sector de clase y la posibilidad de vivir en un sitio confortable, presuntamente más seguro y en contacto con la naturaleza, aunque esto no implique la reproducción de las costumbres rurales, sino solamente otro modo de vivir lo urbano. Por el contrario los grupos de escasos recursos ocupan tierras poco valorizadas -en zonas bajas o inundables-, autoconstruyen sus casas con escasa o nula asistencia técnica e instalan sus propias fronteras mediante carteles $u$ otras señales. 
este contexto la educación de los hijos tiene un lugar preponderante. Los centros educativos que se eligen son de carácter privado y fueron seleccionados principalmente por su doble escolaridad y la enseñanza intensiva de inglés. Estos niños, criados desde pequeños en estas urbanizaciones, no cuentan con las herramientas suficientes para desenvolverse en la ciudad abierta, viven una situación ficticia en tanto que generalmente interactúan con sus pares.

Estas parejas tienen en su mayoría una ocupación formal ${ }^{21}$ que los ubica entre los sectores con ingresos económicos medios y elevados. En las entrevistas que se realizaron se considera en general a este grupo como los nuevos privilegiados ${ }^{22}$ o en términos de Svampa (2001: 39), "los ganadores de la cuestión social". Sin embargo se les podría considerar ganadores antes de mudarse a una urbanización cerrada porque podían elegir, entre otras cosas, adónde vivir. El traslado a estos emprendimientos les permitió poner en evidencia, nuevamente, su posición en la estructura social y el estatus que supuestamente adquieren por vivir en ellas.

Aquellos cuyos ingresos son más elevados eligen vivir en las urbanizaciones cerradas más prestigiosas (por lo general en los countries), y aquellos cuyos ingresos son medios habitan barrios privados y condominios (Malizia, 2011). Al respecto, una residente de una urbanización cerrada opina: "hay que diferenciar entre la gente con y sin plata: la gente con plata se va a vivir al Jockey [Country Jockey Club de Tucumán], piensa todo el tiempo en la ostentación [...] en cambio los que tienen menos plata se van al Golf [Yerba Buena Golf Country Club]" (C., barrio privado Lomas de Yerba Buena, 11/11/08). Asimismo, en las respuestas de los entrevistados también se considera a los residentes como desconfiados y competitivos. Vivir en estos emprendimientos es un intento más por diferenciarse del otro, pero no sólo del que está afuera de la UC sino también de sus pares (que pueden o no vivir en estos emprendimientos), "miran al del frente para ver cómo vive e imitarlo. Esto puede ser real o una metáfora, en mi caso es real, mi vecina del frente todo el tiempo está viendo qué estoy haciendo para imitarme" (K., Yerba Buena Golf Country Club, 10/11/08).

${ }^{21}$ Sus profesiones son variadas: abogados, psicólogos, ingenieros, médicos, docentes, arquitectos, empresarios (vinculados al rubro de la construcción, sobre todo) y propietarios o empleados jerárquicos de comercio.

${ }^{22}$ Esta categoría social fue utilizada en reiteradas oportunidades por los entrevistados. Hace recordar el eslogan que fuera un ícono de los gobiernos peronistas de las décadas de los cuarenta y los cincuenta: "los únicos privilegiados son los niños". 
Finalmente, la elección de las urbanizaciones cerradas como residencia permanente se relaciona principalmente con tres variables. La primera se refiere al contacto con la naturaleza y la elevada contaminación ambiental de San Miguel de Tucumán en comparación con Yerba Buena (el ruido y el smog causado por los automóviles, colectivos y motos; la suciedad de sus calles; la contaminación visual y la saturación del espacio). Este contacto es definido por Svampa (2001: 71) como el "estilo de vida verde" en tanto enfatiza el habitar en lugares rodeados de espacios verdes, en un entorno tranquilo y agradable y en mejores condiciones ambientales, "nos encantó, era un campo divino, todo muy verde alrededor [...] era un sueño" (G., Yerba Buena Golf Country Club, 11/07/07). Se valora el entorno natural en que se emplazan estos emprendimientos, es decir, el municipio Yerba Buena y no las características ambientales internas de la urbanización donde se vive, en tanto se estima que por el solo hecho de habitar en Yerba Buena el contacto con la naturaleza está de alguna manera asegurado.

La segunda variable se relaciona con la seguridad que supuestamente ofrecen las urbanizaciones cerradas y con los deseos de las personas de habitar en lugares donde pueden sentirse protegidas. Se conjugan las percepciones sobre la creciente inseguridad en el aglomerado, las experiencias personales relacionadas con hechos violentos, la sensación de protección que ofrecen estos emprendimientos y la ausencia del Estado. Según Davis (2003) la seguridad adquiere un valor relativo que depende de la renta de las personas y les brinda la posibilidad de acceder a ciertos servicios de protección o ser miembros de un emprendimiento residencial cerrado. El residente de un country explica: "ahora afuera del country no se puede vivir, te afanan, te matan [...] El Estado ya no tiene la capacidad de brindar seguridad. Para mí Yerba Buena es muy tranquilo [...] es muy distinta la vida adentro y afuera del country; afuera ya no hay seguridad" (J., Country Marcos Paz, 15/10/08). De este modo la seguridad se transforma en un bien que, si se desea, se puede comprar, un bien al que sólo pueden acceder algunos grupos sociales que pueden y quieren permitírselo.

La última variable se refiere al sentimiento de comunidad ${ }^{23}$ supuestamente alcanzado en el interior de estos emprendimientos. La oferta principal de estas urbanizaciones radica en la consecución de un estilo de vida diferente junto a la adquisición de un determinado

\footnotetext{
${ }^{23}$ Esta categoría incluye las pretensiones referidas a exclusividad, individualismo y homogeneidad social del grupo de pertenencia.
} 
estatus: vivir en una urbanización cerrada representa, en términos de Bourdieu (1996), mejorar la posición social en la estructura social, "este country es el mejor de Tucumán por el lugar donde está ubicado, la vista que tiene y la cancha de golf que según dicen es la mejor, le da mucha jerarquía [...] Vivir en un country es una cuestión elitista" (U., Yerba Buena Golf Country Club, 21/06/08).

\section{Los de afuera}

Este grupo está integrado por cuatro subgrupos: vecinos próximos a las urbanizaciones cerradas, personas que trabajan en las mismas, actores del ámbito público y privado (agentes inmobiliarios, constructores, urbanistas y representantes del gobierno provincial y municipal) y proveedores de bienes y servicios instalados en zonas colindantes a estos emprendimientos.

El primero, vecinos próximos a las urbanizaciones cerradas, está conformado por los habitantes de Yerba Buena cuyas residencias están localizadas en las proximidades de estos emprendimientos. ${ }^{24}$ Todos ellos viven en la zona desde hace muchos años; de hecho la mayor parte reside en esos lugares desde antes del crecimiento exponencial de estos emprendimientos en el municipio. En sus relatos enfatizaron que la llegada de las UC provocó intensos cambios en el uso del suelo, relacionados sobre todo con el aumento de población: "Yo vivo en la zona hace más de 40 años, me vine para acá cuando me casé $[\ldots]$ antes teníamos un lote de cítricos y verdura que llevábamos para vender en la ciudad, pero ahora nos dedicamos al cultivo de las rosas [...] Todo el tiempo nos hacen ofertas para comprarnos el lote para construir un barrio privado pero no queremos saber nada de vender" (T., vecina de Yerba Buena, 25/07/08). Estos vecinos fueron testigos del inicio del proceso de transición rural-urbana que definió a Yerba Buena en las últimas décadas. Este proceso, que perdura hasta la actualidad, se manifiesta en el reemplazo gradual de actividades agrícolas por actividades urbanas del centro del municipio hacia su periferia.

El siguiente subgrupo incluye a aquellas personas que trabajan, en forma permanente o temporal, en las urbanizaciones cerradas. Se de las UC.

${ }^{24}$ Por proximidad se entiende que sus viviendas colindan con alguno de los límites 
trata de empleadas domésticas, niñeras, guardias de seguridad, jardineros y obreros. Los trabajadores temporales, en cambio, son maestros de apoyo escolar, obreros de la construcción y personas dedicadas al cuidado personal (masajistas y promotoras de productos de belleza). Las exigencias para conseguir un empleo en estas urbanizaciones, aunque sea de baja calificación, son más específicas que las referencias que se suelen solicitar para buscar un trabajo afuera: "en los countries la mayoría entra como obreros [albañiles y pintores] y es posible que algunos se queden como jardineros o como personal de vigilancia del country. Pero para eso ya tienen que ser muy conocidos, ahí tienen que tener buenas referencias" (A., trabajador del Country Jockey Club de Tucumán, 24/07/07). Una vez que se está trabajando adentro de la UC es posible realizar diversas tareas que llevan implícitas diferentes grados de responsabilidad que van aumentando a medida que el trabajador demuestra solvencia. Esta movilidad constituye una forma de ascenso laboral en la urbanización cerrada y social en su entorno de referencia inmediato.

El tercer subgrupo está compuesto por una amplia gama de representantes del ámbito público y privado entre los que destacan agentes inmobiliarios, constructores, vendedores, administradores de las urbanizaciones cerradas, urbanistas y representantes del gobierno provincial y municipal. Este subgrupo se caracteriza por su diversidad ya que incluye a actores sociales con diferentes intereses, sin embargo se les ha agrupado dentro de una misma categoría porque han participado activamente en el proceso de construcción, regulación y comercialización de estos emprendimientos y han conformado un ensamble necesario para que este tipo de urbanizaciones sea exitoso. Por lo tanto sus opiniones resultan importantes para comprender este fenómeno en su conjunto:

Yo creo que los countries [refiriéndose a las urbanizaciones cerradas en general] se expanden de forma fortuita y casual, y generan una cierta concentración económica [...] El crecimiento [de Yerba Buena] fue agolpado, rápido, fuerte y se fue desprendiendo de la capital [San Miguel de Tucumán], aunque las distancias no son muy grandes. Yerba Buena se está cubriendo de muchos servicios que antes no tenía, y en cuanto a lo comercial tiene todo ahí mismo [M., Estudio de Arquitectura Viaña y Molina, 01/08/08].

El último subgrupo, el de los proveedores de bienes y servicios, está integrado por los comercios instalados en las zonas aledañas a 
las urbanizaciones cerradas..$^{25}$ Los comercios que se inauguraron en la última década surgieron en su mayoría como resultado del aumento de la demanda provocada por el incremento de la población: "nosotros pusimos el negocio acá pensado en el barrio privado [Terrazas de San José]" (s/n, carnicería, 31/07/08). La diversificación y la expansión de la oferta están adaptadas a los requerimientos de los distintos grupos sociales que viven en el municipio Yerba Buena. De este modo es posible encontrar desde un negocio exclusivo dedicado a la venta de insumos para jugar el golf hasta una forrajería rural y múltiples polirrubros, herederos actuales de los clásicos almacenes de ramos generales.

\section{"Estar aquí", en el gabinete ${ }^{26}$}

Con el objetivo de mostrar parte de los resultados obtenidos mediante la aplicación de dicha estrategia metodológica se seleccionaron dos ejes de análisis: los vínculos entre quienes viven adentro y quienes viven afuera de las urbanizaciones cerradas, y las percepciones sobre el binomio seguridad/inseguridad. Se partió de una serie de preguntas que actuaron como líneas directrices de la investigación: ¿qué representa estar adentro o afuera de las urbanizaciones cerradas?, ¿qué tipos de vínculos se entablan entre los de adentro y los de afuera?, ¿qué percepciones sustentan unos acerca de los otros?, ¿qué posibilidades laborales genera el fenómeno de las urbanizaciones cerradas?, ¿por qué razones las personas optan por residir en estos emprendimientos de manera permanente?, ¿qué percepciones elaboran sobre el binomio seguridad/ inseguridad en torno a las urbanizaciones cerradas?, ¿las urbanizaciones cerradas proveen seguridad o sensación de seguridad?, ¿los mecanismos de seguridad que brindan las urbanizaciones cerradas son

${ }^{25}$ Aproximadamente el $70 \%$ de estos comercios comenzó a funcionar entre los años 2002 y 2008 y los restantes lo hicieron entre 1978 y 1998. Son principalmente almacenes, verdulerías, panaderías, carnicerías, ferreterías, gomerías, mensajerías, regalerías, polirrubros y farmacias.

${ }_{26}$ Geertz (1988) explica esta etapa al decir que lo importante es fijar "lo dicho" por medio de la escritura, de manera tal que sea susceptible de ser examinado en el futuro: "el etnógrafo 'inscribe' discursos sociales, los pone por escrito, los redacta. Al hacerlo, se aparta del hecho pasajero que existe sólo en el momento en que se da y pasa a una relación de ese hecho que existe en sus inscripciones y que puede volver a ser consultada" (Geertz, 1988: 31). Desde este punto de vista la elaboración teórica no es anterior ni posterior a la tarea de recolección de información, sino soporte del conocimiento mismo y por lo tanto acompaña todo el proceso. 
realmente efectivos a la hora de disminuir o prevenir la ocurrencia de hechos delictivos?

Primer eje de análisis: los vínculos entre quienes viven adentro y quienes viven afuera de las urbanizaciones cerradas

Para Svampa (2004) los estilos de vida adoptados en el interior de las urbanizaciones cerradas conducen a un escaso, si no es que nulo, contacto entre las clases. ${ }^{27}$ Roitman (2004) agrega que los residentes de estos emprendimientos generalmente se relacionan poco o no se relacionan con los habitantes de los barrios situados en sus alrededores, sobre todo con las personas de bajos recursos; sin embargo opina que sí se establecen relaciones de trabajo entre ambos grupos y que están determinadas por las oportunidades laborales que se generan en el interior de estos emprendimientos. Se trata de prestaciones de baja calificación, principalmente de tipo doméstico, que obligan a la interacción cara a cara entre unos y otros. La sociabilidad resultante surge bajo la forma de relaciones funcionales, lo cual deja entrever un componente fuertemente asociado al reconocimiento de las diferencias entre los grupos que acentúan la segregación social.

En general las interacciones entre los de adentro y los de afuera en el municipio Yerba Buena están mediadas por lo económico y combinan la polarización y la interdependencia entre la demanda y la oferta; se logra de esta manera una relación interconectada en lo estrictamente necesario, ya que prima la intención de reducir la dependencia del exterior. Por consiguiente los residentes de las urbanizaciones cerradas buscan ser cada vez más independientes del otro, del que está afuera, por cuanto su mundo transcurre cada vez más en su lugar de residencia. Sin embargo estos emprendimientos, a diferencia de lo que ocurre con algunas urbanizaciones cerradas de Buenos Aires, no están equipados para funcionar como entes separados del resto de la ciudad. Por el contrario, dependen indefectiblemente de la ciudad abierta, de sus servicios urbanos básicos, de su infraestructura comercial y, por supuesto, de sus habitantes, "las urbanizaciones cerradas de Yerba Buena no son autosuficientes, la gente vive adentro de ellas pero después, para

27 Blakely y Synder (2002) consideran que la pérdida de contacto entre grupos sociales debilita los lazos de responsabilidad mutua, lo cual es una parte normal de la vida en comunidad. 
todo lo demás, como las actividades sociales, comerciales, educativas, tienen que salir" (M., Dirección de Planeamiento Urbano, Municipalidad de Yerba Buena, 17/06/07). A partir de los límites establecidos por estos emprendimientos se reorganiza la vida cotidiana de las personas y las relaciones con los otros, teniendo en cuenta que las prácticas sociales que ligan a los habitantes entre sí y con la sociedad en su conjunto varían permanentemente (Svampa, 2004).

Ahora bien, con el fin de identificar el tipo de interacción que se ha establecido se indagó sobre la relación que se entabla entre quienes viven adentro y quienes viven afuera de las urbanizaciones cerradas. A partir de las respuestas obtenidas se construyeron cuatro categorías: directa, indirecta, sin relación y no responde, que giran principalmente en torno a las relaciones laborales o comerciales (Malizia, 2011). Las relaciones directas e indirectas son las que resultan de mayor interés ya que ponen de manifiesto las formas de vinculación de ambos grupos (diagrama 1).

El establecimiento de una relación directa permite la interacción cara a cara (Goffman, 1989) entre los residentes de estos emprendimientos y quienes integran el grupo que presta servicios en su interior, como empleadas domésticas, niñeras, jardineros y guardias de seguridad, entre otros. Aquí el vínculo queda establecido a partir de la interacción del empleador y el empleado: "con la gente para los que trabajo en este barrio nos llevamos muy bien [...] el señor J. [residente del condominio] me presta para regar, desde su jardín, mi huerta [ubicada del otro lado del alambrado del barrio]" (S., condominio Los Cedros, 22/09/08). En este orden también se entablan relaciones, aunque en menor medida, con los proveedores de bienes y servicios instalados en las proximidades de las urbanizaciones cerradas, como verdulerías, carnicerías, panaderías, mensajerías, gomerías y regalerías, entre otros: "viene mucha gente de los countries [refiriéndose a las UC en general] a dejar sus camionetas y autos para lavar, pero ésos son muy especiales porque son unos bacanes, dejan el auto y te piden que se los lleves a su casa porque dicen que están muy ocupados, y cuando vas están sentados tomando mate" (s/n, lavadero de autos Los amigos, 25/07/08).

La relación indirecta, que sólo mencionan los residentes de las urbanizaciones cerradas, se establece en cambio por medio de intermediarios. Este tipo de interacciones pueden entablarse de diferentes maneras, pero son sólo las estrictamente necesarias. Aquellas con los obreros de la construcción (pintores y albañiles, entre otros) son en- 


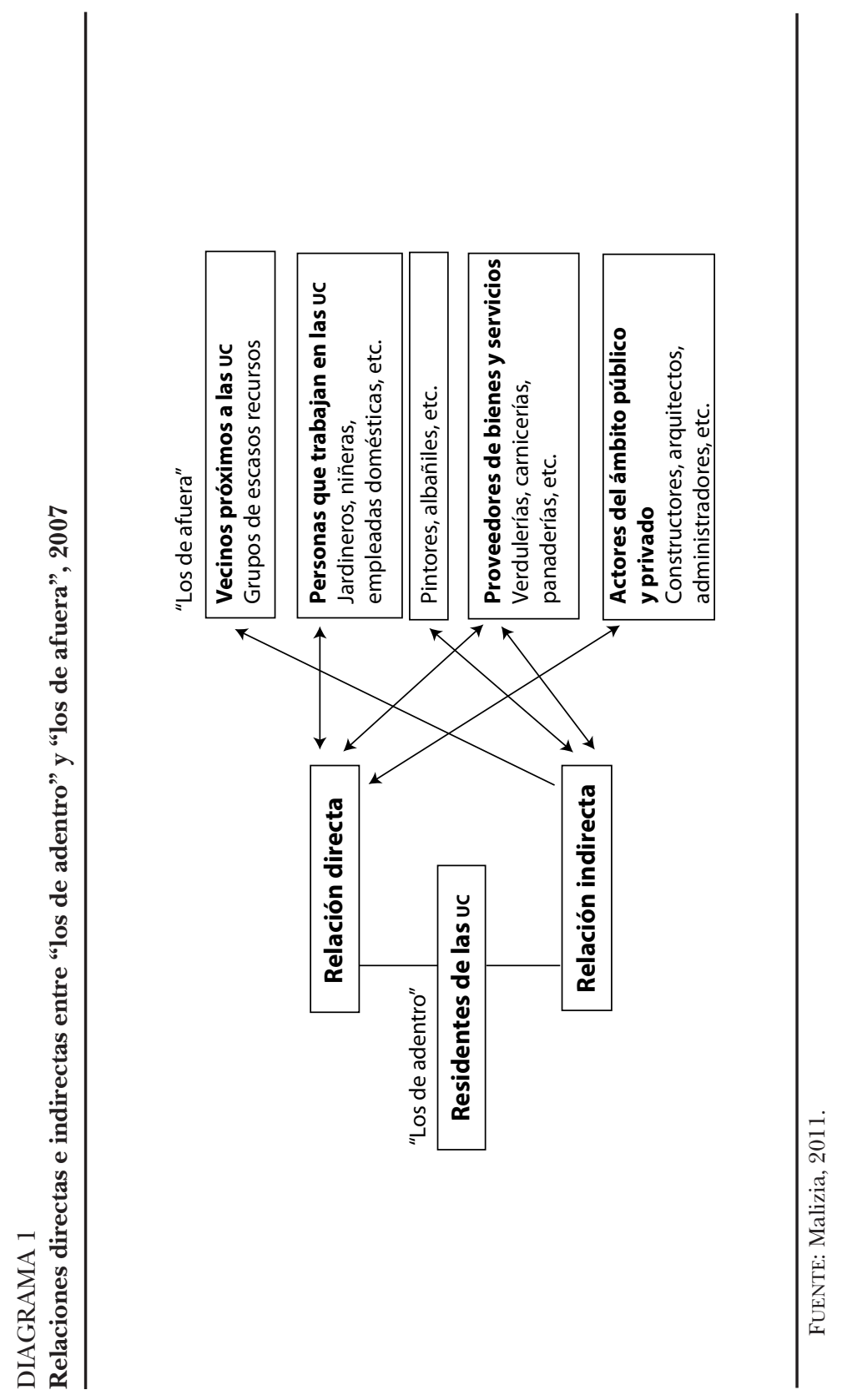


tabladas y mantenidas, en su mayoría, mediante los arquitectos o constructores de las viviendas: "[cuando construyen sus casas] en muchas ocasiones no vienen o vienen muy poco, dejan todo en manos del arquitecto" (S., trabajador del barrio privado Las Colinas II, 04/09/09). Los vínculos comerciales con los negocios instalados en sus alrededores también pueden establecerse en forma indirecta valiéndose del sistema de delivery, y en menor medida por medio del personal doméstico que se encarga de hacer las compras diarias para el funcionamiento del hogar: "la gente de los countries [refiriéndose a todas las UC] vienen y dejan la lista de las cosas que quieren y después se les llevan las cosas a sus casas" (s/n, verdulería La Huertita, $25 / 07 / 08$ ). Asimismo las diversas actividades (como colectas de dinero, alimentos y/o ropa) llevadas adelante por colegios, parroquias y centros comunitarios también forman parte de las relaciones indirectas en tanto son consideradas actividades que median la relación entre los residentes de estos emprendimientos y los sectores de escasos recursos: "se hacen colectas en el country, como la de Caritas, y se llevan a una parroquia que tiene un comedor donde los chicos desayunan, almuerzan y meriendan; el country aporta para ese comedor. En la época de la desnutrición el country juntó de todo para ayudar" (G., Yerba Buena Golf Country Club, 11/07/07).

La tercera categoría se refiere al hecho de no establecer ningún tipo de relación entre los de adentro y los de afuera. Los entrevistados enfatizan que a pesar de mantener vínculos laborales y comerciales, éstos no conducen al establecimiento de relaciones de ninguna índole. Desde esta óptica parecería que ambos grupos simulan e intentan actuar como células independientes sin relación entre sí; sin embargo, en sus relatos se advierte que entablan algunas relaciones absolutamente necesarias: "no hay mucho contacto entre los que viven en los countries y los que viven afuera. Además, ¿cómo van a tener problemas con los de afuera si adentro del country entre ellos, que son vecinos, ni se conocen? No es como en los barrios, que todos se conocen, que son vecinos, que saben quién está a la par" (A., Country Jockey Club de Tucumán, 24/07/07).

Por último, la falta de una respuesta es interpretada como la ausencia total de vínculos entre los de adentro y los de afuera. Esto pone en evidencia que la cercanía espacial no está jugando un rol preponderante en el establecimiento de vínculos entre ambos grupos. El hecho de encontrarse próximos espacialmente no garantiza que se evite que la brecha social continúe profundizándose progresivamente. 
Segundo eje de análisis: las percepciones sobre el binomio seguridad/inseguridad ${ }^{28}$

La promoción y difusión de las urbanizaciones cerradas centra su argumento más importante en el sistema de seguridad (entendido como el cierre y la privatización del emprendimiento) que ofrecen a sus residentes. Por un lado, el territorio ocupado por estos emprendimientos se encuentra delimitado por cercas, muros, rejas o barreras que lo separan del espacio exterior público o privado. Por el otro, cuentan con un acceso restringido y controlado por dispositivos automáticos y por personal de vigilancia privada que generalmente están activos las 24 horas.

Por su parte los medios masivos de comunicación influyen en la percepción de la seguridad y la inseguridad que se viven en las ciudades e impulsan a las personas a modificar su comportamiento. En Argentina, como expresa Igarzábal de Nistal (2006), la prensa escrita, oral y televisiva se ha dedicado en los últimos años a difundir índices de inseguridad que por lo general son el resultado de encuestas poco representativas, cuyos universos son difíciles de comparar entre sí y que no siempre reflejan resultados objetivos derivados de registros oficiales (y aun suponiendo que esos índices fueran reales, no se comparan con los de otros países de la región donde son considerablemente mayores). Se enfatiza cada vez más la idea de que la ciudad abierta dejó de ser segura y la seguridad plena ahora sólo podrá encontrarse en los espacios cerrados, controlados y de acceso restringido. Para Bauman (2009),

la seguridad [...] en un mundo implacablemente individualizado y privatizado, entra en el ámbito del "hágalo usted mismo". "La defensa del lugar", considerada la condición necesaria de toda seguridad, debe ser un asunto del vecindario, una "cuestión comunal". Allí donde ha fracasado el Estado, quizá [...] una comunidad encarnada en un "territorio" habitada por sus miembros y por nadie más (nadie que no pertenezca a ella), provea el sentimiento de "seguridad" [2009: 109-110].

El fin último de sostener el discurso que enfatiza el temor y la inseguridad creciente en las ciudades es estimular la autosegregación de los grupos más acomodados de la sociedad y legitimar la instalación

${ }^{28}$ El binomio seguridad/inseguridad se refiere a la seguridad que ofrecen las UC en contraposición con la imagen de inseguridad creciente que hay en las ciudades. 
de estos emprendimientos en el espacio urbano. La inseguridad se convierte en un ícono valorado que utiliza un determinado sector de la sociedad para demandar y justificar la segregación de ciertos espacios y grupos sociales y para estimular el control y el encierro de las actividades cotidianas, replegando la vida social hacia el interior (Rodríguez Chumillas, 2005). Las urbanizaciones cerradas se erigen como comunidades simuladas que brindan una sensación de bienestar, exclusividad y seguridad, pero que al mismo tiempo recuerdan constantemente los peligros externos y la importancia de mantenerse aislado (López Levi y Rodríguez Chumillas, 2005)..$^{29}$

Las personas elaboran una serie de percepciones que se retroalimentan constantemente en torno al binomio seguridad/inseguridad que dependen del entorno en el que viven, que influyen sobre su comportamiento y toma de decisiones, y que están reforzadas por la posibilidad de ser víctimas de un delito, así como por la desconfianza hacia las instituciones estatales responsables de velar por la seguridad de los ciudadanos y las condiciones ambientales, ya que la inseguridad se asocia a un entorno sucio y desordenado ${ }^{30}$ (Torrente, 2001). Los entrevistados lo explican del siguiente modo: "antes no existía el miedo y la inseguridad. Ahora ni loca vivo afuera de un country, todo está muy inseguro" (G., Yerba Buena Golf Country Club, 11/07/07); "a nosotros nos han entrado ladrones un par de veces y entonces esa inseguridad te invade, uno siempre está inseguro, te sentís vulnerable, en cambio acá [refiriéndose al country en el que vive] es como otra realidad" (M.E., Yerba Buena Golf Country Club, 13/06/08); "yo me he venido [refiriéndose a su mudanza al country] más por seguridad que por otra cosa. Yo quería más seguridad” (J., Yerba Buena Golf Country Club, 23/07/07).

Al comenzar las entrevistas, uno de los argumentos a los que solían acudir los interlocutores para explicar la adopción de estos emprendimientos como residencia permanente era el binomio seguridad/ inseguridad. Enfatizaban que la búsqueda de lugares seguros donde sentirse protegidos terminaba al mudarse a estas urbanizaciones. Sin

${ }^{29}$ En este sentido, dichas autoras observan que la simulación de la seguridad sólo sirve para complacer a la demanda y conduce a la creación de un mundo diferente del que se encuentra afuera. El imaginario sobre inseguridad urbana queda resuelto y con ello se promueve la fantasía de que ésta no existe dentro de su cotidianidad y que, por lo tanto, no representa amenaza alguna.

${ }^{30}$ Sin embargo estas creencias, actitudes y experiencias no necesariamente están relacionadas con el delito real. 
embargo, una vez avanzada la entrevista la mayoría de ellos comenzaba a relatar un conjunto de valoraciones, por lo general contradictorias, en relación con la seguridad y con otros procesos sociales que se generaban al mudarse a estos emprendimientos. El análisis de estas valoraciones puso de manifiesto que vivir en estas urbanizaciones finalmente representaba la obtención de una "sensación de seguridad" que se anteponía a la protección pretendida inicialmente (Malizia, 2012).

El hecho de que las urbanizaciones cerradas brindan una sensación protectora se fundamenta en la imagen que brinda el sistema de seguridad instalado. Se supone que la presencia de dispositivos perimetrales y mecanismos de protección, más que eliminar la ocurrencia de hechos delictivos, provoca un efecto disuasorio ante la intención de cometer un delito contra estos emprendimientos, y por lo tanto limita las sorpresas no deseadas en el interior de estos barrios: ${ }^{31}$

éste es un predio angosto y largo, se necesitaría todo un ejército para dar total seguridad; lo que se contrata es sensación de seguridad, la gente quiere ver al tipo [guardia] caminando por ahí [...] la seguridad es preventiva $[\ldots]$ las personas están equivocadas si creen que vivir en un country o barrio privado es cien por ciento de seguridad, vivir adentro o afuera tiene sus riesgos [L., trabajador del barrio privado Villa Delfina, 27/06/08].

[...] somos una empresa de prevención. La seguridad es una mezcla de prevención y acción: prevenir es evitar que entren al barrio, y si entran viene la parte de la acción [...] Brindamos sensación de seguridad, la idea es que el vecino se sienta seguro porque ellos pagan para sentirse seguros, porque la realidad es que si aparece un grupo comando a tratar de entrar a un barrio, a la seguridad la deja descolocada [...] es todo una cuestión de imagen [G., El Águila Servicios Integrales, 11/09/08].

Asimismo, en la comisaría principal de Yerba Buena declararon que del total de hechos delictivos denunciados por año, aproximadamente la mitad ocurre en relación con las urbanizaciones cerradas: "nosotros sólo tenemos intervención cuando nos llaman [...] De los

31 En una entrevista con la Revista Viva editada por el diario Clarín (5/06/2005), Svampa explica que muchos residentes consideran, ingenuamente, que por contar con vigilancia perimetral las relaciones internas están aseguradas. Sin embargo el crimen de María Marta García Belsunce ocurrido en octubre de 2002 en su residencia del Country Carmel, municipio de Pilar, Buenos Aires, mostró en forma paradigmática las limitaciones de esa ilusión de seguridad absoluta. 
llamados que recibimos, la mitad son eventos afuera de los countries [refiriéndose a todas las urbanizaciones cerradas del área] y la otra mitad son eventos adentro de esos barrios" (O., Comisaría de Yerba Buena, 4/09/09). ${ }^{32}$ Aun cuando estas cifras no pudieron ser comprobadas fehacientemente, se estima que la opinión del agente policial entrevistado no debe estar errada.

De este modo, vivir en estas urbanizaciones representa la obtención de una "sensación de seguridad" que se antepone a la protección pretendida inicialmente, en tanto los mecanismos de seguridad que despliegan estos emprendimientos representan una situación ficticia más que una protección real. Por lo tanto, el hecho de residir en una urbanización cerrada responde más a una estrategia de distinción que a la búsqueda de la seguridad en sí misma. Los dispositivos perimetrales de estos emprendimientos establecen un límite simbólico que representa la distancia existente entre las personas que viven adentro y aquellas que están afuera. Los testimonios de los entrevistados confirman esto: "primero que nada buscan un ascenso social. Después en segundo lugar buscan seguridad [...] se mudan a lugares que les den más estatus social" (J., trabajador del barrio privado Las Colinas, 01/07/08).

\section{Memoria del trabajo de campo}

La permanencia en el campo significó la concurrencia sistemática durante un periodo prolongado de tiempo; "salir" al campo presuponía, siguiendo a Clifford (1999: 72) "una distinción espacial entre una base conocida y un lugar exterior de descubrimiento". En el transcurso de la investigación la permanencia en el campo significó la concurrencia sistemática durante un periodo prolongado de tiempo. El trabajo de campo brindó la posibilidad de observar y registrar una amplia variedad de paisajes urbanos. Su heterogeneidad puso en evidencia contrastes significativos entre los distintos actores sociales: en un lado de la calle se levantaba una villa miseria construida ilegalmente sobre la antigua vía del ferrocarril, y del otro lado, a unos pocos metros, un imponente country. ${ }^{33}$

32 Asimismo el análisis de la tasa de hechos delictivos registrada en la provincia de Tucumán durante el año 2007 puso en evidencia que la tasa para Yerba Buena, de 261.21 por cada diez mil habitantes, era una de las más altas de toda la provincia (Dirección Nacional de Política Criminal, año 2007).

${ }^{33}$ Las villas miseria son la manifestación más clara de la exclusión social. En ellas 
Las técnicas de investigación propuestas dieron la posibilidad de entrar al campo y establecer los contactos necesarios para obtener información que permitiera el análisis y la comprensión del fenómeno de las UC desde la perspectiva de los actores sociales involucrados. La primera actividad concreta fue elaborar la cartografía del área de estudio en tanto la provista por los organismos municipales y provinciales era escasa, desactualizada y muchas veces contradictoria. Disponer de esta cartografía permitió realizar las primeras lecturas del desarrollo urbano de la zona.

Una vez delimitada el área de estudio se comenzó con la realización de las entrevistas. En las urbanizaciones cerradas de Yerba Buena, al igual que en las de otras ciudades del país y de Latinoamérica, no se permite el libre ingreso de personas ajenas a las mismas, salvo que dispongan de una autorización que las habilite; por tal motivo comenzar con las entrevistas supuso entonces tejer una serie de vinculaciones con residentes, actores del ámbito público y privado y empleados que trabajaban dentro de estos emprendimientos. Luego la red fue ampliándose paulatinamente mediante nuevos contactos que facilitaron las personas ya entrevistadas. Durante estos encuentros las personas relataban sus historias, contaban sus experiencias de vida, estaban dispuestas a entablar el diálogo y manifestaban con entusiasmo su interés por opinar. ${ }^{34}$ Dichas entrevistas ofrecieron nuevas y diferentes perspectivas sobre la realidad en estudio. En la actualidad se continúa recorriendo el campo y registrando todo lo que allí acontece.

\section{A modo de conclusión}

La estrategia metodológica propuesta, enmarcada en la lógica de la investigación cualitativa y basada en un enfoque etnográfico, resultó

\footnotetext{
habitan, siguiendo a Bauman (2005), los residuos humanos o, para ser más exactos, los seres humanos residuales o superfluos. Estas personas son consideradas como los desechos de la globalización y no encajan ni se les puede hacer encajar en los diseños de la modernidad. Se establece una frontera entre los seres humanos residuales y los no residuales que pone en evidencia las diferencias entre ellos: entre lo admitido y lo rechazado, lo incluido y lo excluido. Si bien las causas de la exclusión pueden ser distintas, para quienes la padecen los resultados son los mismos.

${ }^{34}$ Un antropólogo, Mario Rabey, para bajar la ansiedad de sus estudiantes de grado solía decirles que para entablar una conversación en el campo sólo bastaba decir "cuénteme de su vida". Hago esta aclaración porque yo también pensé que me encontraría con reiteradas negativas en el momento de realizar las entrevistas.
} 
pertinente para analizar el efecto socioespacial de las urbanizaciones cerradas en la trama urbana, los cambios en la dinámica social vigente en el área que las contiene, y las percepciones e interacciones sostenidas por las personas involucradas, los de adentro y los de afuera. La mirada se centró en las percepciones, la representación y los vínculos que los actores sociales participantes despliegan ante este fenómeno urbano.

Su utilización dio la posibilidad de analizar en profundidad diversas situaciones, percepciones y relaciones que se han instaurado en torno a estos emprendimientos residenciales. Permitió lograr una comprensión contextual del objeto de estudio y obtener resultados que constituyen un tipo de conocimiento susceptible de ser comparado con los resultados que se han producido en contextos similares.

El surgimiento de las urbanizaciones cerradas conjuga las demandas de las personas que pretenden habitar en lugares donde se sientan protegidas, en contacto con la naturaleza y, en cierta forma, separadas del resto de otros habitantes de la ciudad; en ello influyen tanto los medios de comunicación como los especuladores inmobiliarios. La combinación de tales condiciones se produce en un momento histórico que Bauman (2005) define como "modernidad líquida". Una de sus características básicas es la profundización del proceso creciente de individualización social, donde las relaciones sociales comunitarias se han vuelto líquidas, transitorias y volátiles. ${ }^{35}$ No obstante, estas urbanizaciones dependen indefectiblemente para su funcionamiento del resto de la ciudad, de sus servicios urbanos básicos, de su infraestructura comercial, y por supuesto, de sus habitantes, dado que no están equipadas para funcionar como entes totalmente aislados.

De este modo se establecen permanentemente interacciones entre los de adentro y los de afuera que influyen en la dinámica social y urbana. En dicha dinámica se ponen en evidencia los actuales matices que adquieren la fragmentación espacial y la segregación social, entendidas como dos instancias que no pueden ser consideradas por separado (Valenzuela Aguilera, 2002). Pese a que en el área de estudio ambos grupos se encuentran próximos espacialmente, la distancia social que los separa es cada vez más notable. La cercanía y las interacciones entabladas no son suficientes para evitar que la brecha que los separa se profundice progresivamente. Los muros, rejas y alambrados que se

35 Este autor caracteriza a la modernidad como un tiempo líquido que da cuenta del tránsito de una modernidad sólida, estable y repetitiva, a una líquida, flexible y voluble, en que las estructuras sociales ya no perduran el tiempo necesario para solidificarse y no sirven de marco de referencia para los actos humanos. 
erigen se convierten en barreras sociales que marcan profundas diferencias entre quienes viven adentro y quienes viven afuera de estos emprendimientos. Esto parece coincidir con las aseveraciones de Hobsbawm (1997), para quien uno de los aspectos más perturbadores de la vida actual es la ruptura de los vínculos sociales. La sociedad queda constituida, entonces, por un conjunto de individuos con características egocéntricas, desconectados entre sí y que persiguen su propia gratificación.

La ciudad, entendida originariamente como un espacio de encuentro, se va desdibujando hasta convertirse en un espacio fragmentado en el cual la segregación liga los fenómenos sociales con los lugares en los cuales se inscriben. La organización territorial de la ciudad y los lazos que establecen entre sí los grupos que la habitan resaltan su desigual distribución en ésta y su acceso diferenciado a los recursos materiales y simbólicos, poniendo de manifiesto una amplia desigualdad socioterritorial. Los muros, alambrados y sistemas de seguridad establecidos en los límites de las UC se convierten en símbolos que organizan las diferencias en el espacio urbano. En definitiva, el miedo, el consumo y la simulación aparecen, entonces, como los factores que atraviesan los discursos de los entrevistados e impregnan sus percepciones respecto a este fenómeno urbano.

\section{Bibliografía}

Achilli, Elena (2005), Investigar en antropología social. Los desafíos de transmitir un oficio, Rosario, Labor de Libros.

Arizaga, María Cecilia y Ana María Murgida (2005), "La pequeña Australia. La experiencia de las nuevas fronteras de las urbanizaciones cerradas”, en Max Welch Guerra (coord.), Buenos Aires a la deriva. Transformaciones urbanas recientes, Buenos Aires, Biblos, pp. 430-445.

Batallán, Graciela (2007), Docentes de infancia. Antropología del trabajo en la escuela primaria, Buenos Aires, Paidós.

Bauman, Zygmund (2005), Vidas desperdiciadas: la modernidad y sus parias, Barcelona, Paidós Ibérica.

Bauman, Zygmund (2008), Amor líquido. Acerca de la fragilidad de los vínculos humanos, Buenos Aires, Fondo de Cultura Económica.

Bauman, Zygmund (2009), Comunidad. En busca de la seguridad en un mundo hostil, Madrid, Siglo XXI.

Berreman, Gerald (1962), "Detrás de muchas máscaras. Etnografía y manejo de las impresiones de un pueblo del Himalaya", Monografía, núm. 4, California, Society for Applied Anthropology. 
Blakely, Edward y Mary Snynder (2002), "Comunidades fortificadas: amurallamiento y enrejamiento de los suburbios estadounidenses”, Eure, vol. 28, núm. 84, pp. 145-147.

Boivin, Mauricio, Ana Rosato y Victoria Aribas (1999), Constructores de otredad, Buenos Aires, Editorial Universitaria de Buenos Aires.

Borsdorf, Axel (2003), "Cómo modelar el desarrollo y la dinámica de la ciudad latinoamericana”, Eure, vol. 29, núm. 86, pp. 37-49.

Borsdorf, Axel y Rodrigo Hidalgo (2004), "Formas tempranas de exclusión residencial y el modelo de la ciudad cerrada en América Latina. El caso de Santiago", Norte Grande, vol. 32, pp. 21-37.

Bourdieu, Pierre (1996), Cosas dichas, Barcelona, Gedisa.

Cabrales Barajas, Luis Felipe (2002), Latinoamérica: países abiertos, ciudades cerradas, Guadalajara, Universidad de Guadalajara / UNESCO.

Cabrales Barajas, Luis Felipe (2004), "Urbanizaciones cerradas en Latinoamérica”, Ería, núm. 63, pp. 53-57.

Caldeira, Teresa (2007), Ciudad de muros, Barcelona, Gedisa.

Carballo, Cristina (2002), "Buenos Aires y las urbanizaciones cerradas: nuevas formas de apropiación del espacio urbano", en Luis Cabrales Barajas (comp.), Latinoamérica: países abiertos, ciudades cerradas, Guadalajara, Universidad de Guadalajara / UNESCO, pp. 237-259.

Cardozo de Oliveira, Roberto (2004), "El trabajo del antropólogo: mirar, escuchar, escribir”, Revista de Antropología AVA, núm. 5, pp. 55-89.

Clifford, James (1999), Itinerarios transculturales, Madrid, Gedisa.

Cueto, Carla del (2007), Los únicos privilegiados. Estrategias educativas de familias residentes en countries y barrios cerrados, Buenos Aires, Prometeo Libros.

Curtit, Guillermo (2003), Ciudad, gestión local y nuevos desafíos ambientales. Reflexiones en torno a las políticas neoliberales y sus efectos sobre nuestros territorios, Buenos Aires, Espacio / Centro de Investigaciones Ambientales.

Davis, Mike (2003), Ciudad de cuarzo. Arqueología del futuro en Los Ángeles, Madrid, Lengua de Trapo.

Gadamer, Hans-Georg (1993), Verdad y método I. Fundamentos de una hermenéutica filosófica, Madrid, Sígueme.

García Canclini, Néstor (1996), "Público-privado: la ciudad desdibujada”, Alteridades, vol. 6 , núm. 11, pp. 5-10.

Geertz, Clifford (1988), La interpretación de las culturas, Madrid, Gedisa.

Geertz, Clifford (1989), El antropólogo como autor, Madrid, Paidós.

Giddens, Anthony (1989), "Hermenéutica, etnometodología y problemas del análisis interpretativo”, Cuadernos de Antropología Social, vol. 2, núm. 1, pp. 71-77.

Girola, Florencia (2008), "Modernidad histórica, modernidad reciente. Procesos urbanos en el Área Metropolitana de Buenos Aires: los casos del Conjunto Soldati y Nordelta”, tesis doctoral, Buenos Aires, Facultad de Filosofía y Letras, Universidad Nacional de Buenos Aires. 


\section{Malizia, EL ESTUDIO DE LAS URBANIZACIONES CERRADAS}

Goetz, Judith P. y Margaret D. LeCompte (1988), Etnografía y diseño cualitativo en investigación educativa, Madrid, Morata.

Goffman, Erving (1989), La presentación de la persona en la vida cotidiana, Buenos Aires, Amorrortu.

Guber, Rosana (2001), La etnografía. Método, campo y reflexividad, Buenos Aires, Norma.

Guber, Rosana (2009), El salvaje metropolitano, Buenos Aires, Legasa.

Hidalgo, Rodrigo (2004), "De los pequeños condominios a la ciudad vallada: las urbanizaciones cerradas y la nueva geografía social en Santiago de Chile”, Eure, vol. 30, núm. 91, pp. 29-52.

Hammersley, Martin y Paul Atkinson (1994), Etnografía. Métodos de investigación, Barcelona, Paidós.

Hobsbawm, Eric (1997), Historia del siglo XX: 1914-1991, Barcelona, Crítica Grijalbo Mondadori.

Igarzábal de Nistal, María Adela (2006), "Enfoque espacial de la problemática del delito aplicado a la ciudad autónoma de Buenos Aires", en Pedro Fraile et al. (coord.), Paisaje ciudadano, delito y percepción de la inseguridad. Investigación interdisciplinaria del medio urbano, Madrid, Instituto Internacional de Sociología Jurídica de Oñati / Dykinson, pp. 29-52.

Janoschka, Michael (2002), "Urbanizaciones privadas en Buenos Aires: ¿hacia un nuevo modelo de ciudad latinoamericana?”, en Felipe Cabrales Barajas (comp.), Latinoamérica: países abiertos, ciudades cerradas, Guadalajara, Universidad de Guadalajara / UNESCO, pp. 287-318.

Janoschka, Michael (2005), "El modelo de ciudad latinoamericana. Privatización y fragmentación del espacio urbano de Buenos Aires: el caso Nordelta”, en Max Welch Guerra (coord.), Buenos Aires a la deriva: transformaciones recientes, Buenos Aires, Biblos.

Janoschka, Michael y Georg Glasze (2003), "Urbanizaciones cerradas: un modelo analítico", Ciudades, núm. 59, pp. 9-20.

Lacarrieu, Mónica (2002), "La comunidad: el mundo imaginario en las urbanizaciones privadas en Buenos Aires", en Felipe Cabrales Barajas (comp.), Latinoamérica: países abiertos, ciudades cerradas, Guadalajara, Universidad de Guadalajara / UNESCO, pp. 177-214.

Lacarrieu, Mónica y Guy Thuillier (2001), "Las urbanizaciones privadas en Buenos Aires y su significación”, Perfiles Latinoamericanos, núm. 19, pp. 83-113.

Lipovetsky, Gilles (2002), El imperio de lo efimero, Barcelona, Anagrama.

López Levi, Liliana e Isabel Rodríguez Chumillas (2004), "Miedo y consumo: el encerramiento habitacional en Madrid y México”, Perspectivas Urbanas, núm. 5, pp. 21-32.

López Levi, Liliana e Isabel Rodríguez Chumillas (2005), "Evidencias y discursos del miedo en la ciudad: casos mexicanos", Scripta Nova, vol. 9, núm. 194 (54)<ub.edu/geocrit/nova.htm> (mayo de 2013). 
Low, Setha (2003), Behind the Gates. Life, Security and the Pursit of Happiness in Fortress America, Nueva York, Routledge.

Malizia, Matilde (2011), "Countries y barrios privados en el Gran San Miguel de Tucumán. Efectos y contrastes sociales”, tesis de doctorado, Tucumán, Facultad de Filosofía y Letras, Universidad Nacional de Tucumán.

Malizia, Matilde (2012), "La seguridad en las urbanizaciones cerradas: mito o realidad. El caso de Yerba Buena, Argentina", Ciudad y Territorio. Estudios Territoriales, vol. 44, núm. 172, pp. 335-347.

Méndez, Eloy (2002), "Espacios de la simulación”, en Felipe Cabrales Barajas (comp.), Latinoamérica: países abiertos, ciudades cerradas, Guadalajara, Universidad de Guadalajara / UNESCO, pp. 65-90.

Mertins, Günter (2003/2004), "Ciudades nuevas / ciudades privadas", Población y Sociedad, núms. 10-11, pp. 183-192.

Rabey, Mario y Beatriz Kalinsky (1991), "El contrato cognoscitivo (los antropólogos también son seres humanos)", Cuadernos de Epistemología de las Ciencias Sociales, núm.1, pp.19-42.

Ricouer, Paul (1988), Hermenéutica y acción, Buenos Aires, Docencia.

Rockwell, Elsie (1987), "Notas sobre el proceso etnográfico (1982-1985)", México, Dirección de Investigaciones Educativas (mimeo.).

Rodríguez Chumillas, Isabel (2005), “¿‘Privatopía’ versus ciudad pública? La materialización del miedo en el espacio urbano”, en Obdulia Gutiérrez (coord.), La ciudad y el miedo, Barcelona, Grupo de Geografía Urbana de la Asociación de Geógrafos Españoles / Universitat de Girona, pp. 127-135.

Roitman, Sonia (2004), "Urbanizaciones cerradas: estado de la cuestión hoy y propuesta teórica”, Norte Grande, vol. 32, pp. 5-19.

Rojas, Patricia (2007), Mundo privado. Historias de vida en countries, barrios y ciudades cerradas, Buenos Aires, Planeta / Seix Barral.

Sontag, Susan (2007), Al mismo tiempo. Ensayos y conferencias, Barcelona, Mondadori.

Souza Minayo, María Cecilia (comp.) (2004), Investigación social. Teoría, método y creatividad, Buenos Aires, Lugar.

Svampa, Maristella (2001), Los que ganaron. La vida en los countries y barrios privados, Buenos Aires, Biblos.

Svampa, Maristella (2002), "Las nuevas urbanizaciones privadas. Sociabilidad y socialización: la integración social hacia arriba”, en Luis Beccaria et al. (coord.), Sociedad y sociabilidad en la Argentina de los 90, Buenos Aires, Universidad Nacional de General Sarmiento / Biblos, pp. 55-95.

Svampa, Maristella (2004), La brecha urbana. Countries y barrios privados, Buenos Aires, Capital Intelectual.

Taylor, Steven J. y Robert Bogdan (1990), Introducción a los métodos cualitativos de investigación. La búsqueda de significados, Buenos Aires, Paidós.

Tella, Guillermo (2000), "La modernización tardía de una metrópolis semiperiférica: el caso de Buenos Aires y sus transformaciones socio territoriales recientes", Scripta Nova, vol. 69, núm. $70<$ ub.edu/geocrit/nova.htm> (mayo de 2013). 
Thuillier, Guy (2005), "El impacto socioespacial de las urbanizaciones cerradas: el caso de la Región Metropolitana de Buenos Aires”, Eure, vol. 31, núm. 93, pp. 5-20.

Torrente, Diego (2001), Desviación y delito, Madrid, Alianza.

Valenzuela Aguilera, Alfonso (2002), "Las nuevas centralidades. Fragmentación, espacio público y ciudadanía”, en Felipe Cabrales Barajas (comp.), Latinoamérica: países abiertos, ciudades cerradas, Guadalajara, Universidad de Guadalajara / UNESCO, pp. 31-64.

Velázquez, Guillermo y Juan Pablo Celemin (2013), La calidad ambiental en Argentina. Análisis regional y departamental, Buenos Aires, Universidad Nacional del Centro de la Provincia de Buenos Aires.

Vidal Koppmann, Sonia (2006), "La articulación global-local o cuando los actores privados construyen una nueva ciudad”, Scripta Nova, vol. 10, núm. 218 (39) <ub.edu/geocrit/nova.htm> (mayo de 2013).

Vidal Koppmann, Sonia (2007), "Transformaciones socioterritoriales de la Región Metropolitana de Buenos Aires en la última década del siglo XX. La incidencia de las urbanizaciones privadas en la fragmentación de la periferia”, tesis de doctorado, Buenos Aires, Facultad Latinoamericana de Ciencias Sociales (Flacso).

Von Wright, Gerog Henrik (1971), Explicación y compresión, Madrid, Alianza.

Yuni, José A. y Claudio Urbano (2003), Recursos metodológicos para la preparación de proyectos de investigación, vol. 2, Córdoba, Brujas.

\section{Acerca de la autora}

Matilde Malizia es licenciada en Trabajo Social y doctora en Ciencias Sociales con orientación en Geografía por la Universidad Nacional de Tucumán. Sus temas de interés se engloban en la geografía urbana, particularmente en los procesos territoriales y de expansión urbana vinculados con diversas lógicas de ocupación del espacio. Ha publicado diversos artículos y capítulos de libros relacionados con esta temática en ámbitos nacionales e internacionales. Actualmente es becaria posdoctoral del Consejo Nacional de Investigaciones Científicas y Técnicas (Conicet) de Argentina. Forma parte de los proyectos de investigación "La Argentina fragmentada: territorios y sociedades en la primera década del siglo XXI" (Conicet), dirigido por el doctor Pablo Paolasso; y "Riesgos y oportunidades del cambio global en el noroeste argentino. Dinámicas socioterritoriales, estrategias de adaptación y sustentabilidad regional" (BMWF), dirigido por los doctores Pablo Paolasso y Martin Coy. Es miembro del comité editorial de la revista Población \& Sociedad. 
